\title{
Liposomal Delivery of Demineralized Dentin Matrix for Dental Tissue Regeneration
}

\author{
Genevieve E. Melling, PhD,-3 John S. Colombo, PhD, Steven J. Avery, PhD, 1,3 Wayne Nishio Ayre, PhD, \\ Samuel L. Evans, $\mathrm{PhD}^{3,5}$ Rachel J. Waddington, $\mathrm{PhD}^{1,3}$ and Alastair J. Sloan, $\mathrm{PhD}^{1,3}$
}

Current dental restorations have short longevity, and consequently, there is a need for novel tissue engineering strategies that aim to regenerate the dentin-pulp complex. Dentin matrix contains a myriad of bioactive growth factors and extracellular matrix proteins associated with the recruitment, proliferation, and differentiation of dental pulp progenitor cells. In this study, we show that demineralized dentin matrix (DDM), from noncarious dentine, can be encapsulated into liposomes for delivery to dental tissue to promote regeneration. Liposomes were formulated to encapsulate $0-100 \mu \mathrm{g} / \mathrm{mL}$ DDM, lysed with Triton $\mathrm{X}$, and used in vascular endothelial growth factor (VEGF) and transforming growth factor- $\beta 1$ (TGF- $\beta 1$ ) enzyme-linked immunosorbent assays to quantify release. The encapsulation efficiencies were calculated to be $25.9 \%$ and $28.8 \%$ (VEGF/TGF- $\beta 1$ ) for $50 \mu \mathrm{g} / \mathrm{mL}$ DDM liposomes and 39\% and 146.7\% (VEGF/TGF- $\beta 1$ ) for $100 \mu \mathrm{g} / \mathrm{mL}$ DDM liposomes. All liposome formulations had no cytotoxic effects on a dental pulp stem cell (DPSC) clone, as shown by MTT (3-(4,5dimethylthiazol-2-yl)-2,5-diphenyltertrazolium bromide), Caspase 3/7 assays, and cell counts. The ability of the liposomes to stimulate DPSC chemotactic recruitment was tested by Boyden chamber chemotaxis assays. Unloaded liposomes alone stimulated significant progenitor cell recruitment, while DDM-loaded liposomes further promoted chemotactic recruitment in a dose-dependent manner. DDM liposomes promoted the upregulation of "osteodentin" markers osteocalcin and RUNX2 (Runt-related transcription factor 2) in DPSCs after 9 days of treatment, determined by real-time quantitative PCR. Furthermore, Alizarin Red S staining showed that unloaded liposomes alone induced biomineralization of DPSCs, and DDM liposomes further increased the amount of mineralization observed. DDM liposomes were more effective than free DDM $(10 \mu \mathrm{g} / \mathrm{mL})$ at activating recruitment and osteogenic differentiation of DPSC, which are key events in the endogenous repair of the dentin-pulp complex. The study has highlighted the therapeutic potential of bioactive DDM liposomes in activating dental tissue repair in vitro, suggesting that liposomal delivery from biomaterials could be a valuable tool for reparative dentistry and hard-tissue engineering applications.

Keywords: dental tissue engineering, liposomes, demineralized dentin matrix, odontogenesis, dental pulp stem cells, reparative dentinogenesis, restorative materials

\section{Introduction}

$\mathbf{I}$ N RESPONSE TO DEMINERALIZATION from trauma- or caries-induced acid injury, the dentin-pulp complex can undergo reparative dentinogenesis. This involves dental pulp stem cells (DPSCs) being recruited to below the site of injury and differentiating into odontoblast-like cells, which produce tertiary/reparative dentin ${ }^{1,2}$ to protect the underlying dentin. The mechanisms behind this endogenous response are not fully delineated; however, the noncollagenous bioactive protein component of dentin is thought to play a key role.

\footnotetext{
${ }^{1}$ Department of Oral and Biomedical Sciences, School of Dentistry, Cardiff University, Cardiff, United Kingdom.

${ }^{2}$ Department of Biological and Medical Sciences, Oxford Brookes University, Oxford, United Kingdom.

${ }^{3}$ Cardiff Institute for Tissue Engineering and Repair (CITER), Cardiff, United Kingdom.

${ }_{5}^{4}$ School of Dentistry, University of Utah, Salt Lake City, Utah.

${ }^{5}$ School of Engineering, Cardiff University, Cardiff, United Kingdom.
}

(c) Genevieve E. Melling et al. 2018; Published by Mary Ann Liebert, Inc. This is an Open Access article distributed under the terms of the Creative Commons Attribution License, which permits unrestricted use, distribution, and reproduction in any medium, provided the original work is properly cited. 
Dentin contains a plethora of growth factors and matrix proteoglycans, which are involved with the differentiation, survival, migration, and proliferation of DPSCs and mineralization of predentin. ${ }^{3}$ Studies have highlighted that demineralized dentin matrix (DDM) and soluble whole tooth extract $^{4}$ can induce matrix mineralization, in addition to dental papilla cell ${ }^{5}$ and DPSC differentiation. ${ }^{6}$ Our previous work has highlighted the bioactivity of DDM in dentin and bone repair, including its ability to promote survival, cell expansion, osteogenesis, and mineralization in DPSCs ${ }^{6}$ and bone marrow mesenchymal stem cells (BMMSCs). ${ }^{7}$ In addition, in vivo studies have shown its ability to promote bone and dentin regeneration. ${ }^{8-10}$

Despite the capacity of dentin to endogenously regenerate, the process is overwhelmed in the case of large lesions. Failure to regenerate dentin results in further exposure of the vital pulp which, if left untreated, can lead to irreversible pulpitis, the treatment for which is endodontic therapy or whole tooth extraction. In addition to these, there is an increased risk of abscess formation and systemic infections. Currently, the most common treatment is to remove the carious dentin and fill with an inert amalgam or composite material. The current success rates of restorative dental treatments are variable, with around $50 \%$ of restorations failing within 10 years $^{11}$ and around $25 \%$ of endodontic treatments failing. ${ }^{12}$ Recent research has aimed to identify small molecules that could be used in restorative materials to regenerate the dentin-pulp complex, for example, glycogen synthase kinase (GSK3) antagonists ${ }^{13}$ and dentin sialoprotein (DSP). ${ }^{14}$ Previous work from our group and others ${ }^{15-17}$ have investigated harnessing the bioactivity of DDM in dental restorations, by testing the use of etching/conditioning agents to liberate sequestered growth factors within dentin.

Liposomes are amphiphilic lipid vesicles, which selfassemble in an aqueous environment. They are capable of protecting their cargo from proteolytic degradation by encapsulating drugs both in the lipid bilayer and the aqueous core, depending on the agent's hydrophobicity. Liposomes are excellent tools for controlled, sustained drug delivery ${ }^{18}$ and have been used to deliver a range of molecules to engineer tissue and stimulate endogenous repair. ${ }^{19}$ The aim of this study was to investigate the ability of bioactive liposomes containing DDM to induce a mineralizing phenotype to promote reparative dentinogenesis.

In this study, phosphatidylserine containing liposomes, a lipid which has been shown to promote bone mineralization, ${ }^{20,21}$ was used to encapsulate and deliver DDM to a DPSC clone to promote mineralized tissue repair in vitro.

\section{Materials and Methods}

\section{Materials}

Phosphatidylcholine from egg yolk ( $\geq 99.0 \%)$, phosphatidylserine from Glycine max (soybean; $\geq 97 \%$ ), and cholesterol $(\geq 99.0 \%)$. Reagents were, unless otherwise stated, purchased from Sigma-Aldrich.

\section{Routine cell culture}

The primary human dental pulp stem cells (hDPSCs) colony A3 was isolated as previously described, ${ }^{22}$ and cultured in $\alpha$-MEM (containing ribonucleosides and deoxyribonu- cleosides) supplemented with $10 \%(\mathrm{v} / \mathrm{v})$ heat-inactivated fetal bovine serum (ThermoFisher), $4 \mathrm{mM}$ L-glutamine (ThermoFisher), $100 \mu \mathrm{M}$ L-Ascorbate 2-phosphate, 100 units/mL penicillin $\mathrm{G}$ sodium, $0.1 \mu \mathrm{g} / \mathrm{mL}$ streptomycin sulfate, and $0.25 \mu \mathrm{g} / \mathrm{mL}$ amphotericin.

\section{Preparation of DDM}

DDM was prepared using extracted human teeth from informed, consenting patients at the Cardiff University School of Dentistry, University Hospital Wales. Ethical approval was granted by the Research Ethics Committee under South East Wales Tissue Bank approval (12/WA/028). The DDM was prepared as previously described. ${ }^{7}$ The lyophilized DDM was reconstituted in Tris-buffered saline (TBS). Total protein was measured using a BCA (bicinchoninic acid) assay (ThermoFisher) and diluted in TBS $(0-100 \mu \mathrm{g} / \mathrm{mL})$.

\section{Preparation of DDM liposomes}

Lipids were dissolved in chloroform (ThermoFisher) at $1 \mathrm{mg} / \mathrm{mL}(\mathrm{w} / \mathrm{v})$ at a ratio of 7:2:1 (w/w) phosphatidylcholine:phosphatidylserine:cholesterol. Chloroform was removed by rotary evaporation (BUCHI Rotavapor R-300) at $332 \mathrm{mbar}$ for $15 \mathrm{~min}$ (water bath at $50^{\circ} \mathrm{C}$ ) or until a dry lipid film was produced. Liposomes were formed by resuspending the lipid bilayer film in DDM/TBS to a final concentration of $1 \mathrm{mg} / \mathrm{mL}$ (w/v). Liposome batches were then extruded, using a Lipex extruder (Northern Lipids), through a $100 \mathrm{~nm}$ polycarbonate filter 10 times to produce small unilamellar liposome vesicles of $\sim 100 \mathrm{~nm} \pm 20 \mathrm{~nm}$. The liposomes were sized by dynamic light scattering using a Zetasizer Nano ZS (Malvern). Unentrapped material was removed by Sephadex G50 column separation or ultracentrifugation (Sorvall Discovery 100SE ultracentrifuge) at $100,000 \mathrm{~g}$ for $1 \mathrm{~h}$ at $4^{\circ} \mathrm{C} .^{23}$

\section{Assessment of DDM encapsulation into liposomes}

Liposomes were separated from unentrapped material by Sephadex G50 column filtration, as describe in reference $23,{ }^{23}$ and were subsequently lysed with $1 \%$ (v/v) Triton $\mathrm{X}$ and the amount of vascular endothelial growth factor (VEGF) and transforming growth factor- $\beta 1$ (TGF- $\beta 1$ ) release was determined using a commercial enzyme-linked immunosorbent assay (ELISA) (VEGF; R\&D Systems and TGF$\beta 1$; ThermoFisher), following manufacturer's instructions.

\section{Cell treatments}

A3 DPSCs $\left(2.2 \times 10^{4} / \mathrm{cm}^{2}\right)$ were seeded in six-well plates and treated with DDM liposomes at concentrations of $0-100 \mu \mathrm{g} / \mathrm{mL}$ (lipid concentration), free DDM $(10 \mu \mathrm{g} / \mathrm{mL})$, or osteogenic media (supplemented $\alpha$-MEM plus $10 \mathrm{nM}$ dexamethasone and $100 \mu \mathrm{M} \beta$-glycerophosphate) for 3,9 , 21 , and 35 days. DDM liposomes (DDM concentrations of $0,1,10$, and $100 \mu \mathrm{g} / \mathrm{mL}$ ) were ultracentrifuged, resuspended in supplemented $\alpha$-MEM and sterile filtered. After treatments, cells were scraped in RLT RNA lysis buffer (Qiagen) for molecular analysis.

\section{Cytotoxicity assays}

A3 DPSCs $\left(1 \times 10^{4} / \mathrm{cm}^{2}\right)$ were seeded in 96-well plates (white walled for the Caspase-Glo 3/7 assay; Greiner Bio- 
One). DPSCs were treated with DDM liposomes $(0-100 \mu \mathrm{g} /$ $\mathrm{mL} \mathrm{DDM})$ at liposome concentration of $10 \mathrm{ng} / \mathrm{mL}$, for 3,9 , and 21 days. After 3 days, a Caspase-Glo 3/7 assay (Promega) was performed by adding 1 volume of Caspase-Glo 3/7 reagent and incubating for $1 \mathrm{~h}$ at room temperature before measuring luminescence. Cell viability was assessed by an MTT (3-(4,5-dimethylthiazol-2-yl)-2,5-diphenyltertrazolium bromide) assay. Twenty-five microliters MTT solution $(5 \mathrm{mg} / \mathrm{mL})$ was added to DPSCs and incubated for $3 \mathrm{~h}$ at $37^{\circ} \mathrm{C}$, media aspirated, and the MTT precipitate solubilized by the addition of $100 \mu \mathrm{L}$ dimethyl sulfoxide. Absorbance was measured at $570 \mathrm{~nm}$, with a reference at $630 \mathrm{~nm}$. Cells in additional wells were also counted after 3 days.

\section{Boyden transwell recruitment assay}

DPSCs $\left(1 \times 10^{5}\right)$ were seeded into transwell inserts and placed on top of media containing liposomes $(100 \mu \mathrm{g} / \mathrm{mL})$. Recruited cells attached to the transwell inserts were washed with phosphate-buffered saline (PBS), fixed with $10 \%(\mathrm{v} / \mathrm{v})$ formaldehyde, stained with $0.1 \%$ (w/v) crystal violet, and imaged in PBS at $20 \times$ magnification on a Nikon Eclipse TS100 light microscope. Representative images were taken, and cells were counted using ImageJ image analysis software $(\mathrm{NIH})$.

\section{Quantitative real-time PCR}

RNA was isolated using the RNeasy Kit (Qiagen), following manufacturer's instructions. RNA yield was quantified using a NanoVue spectrophotometer (GE Healthcare). Total RNA $(1 \mu \mathrm{g})$ was used to generate total complementary DNA (cDNA) using M-MLV Reverse Transcriptase (Promega). Osteogenic marker expression was analyzed in a SYBR Green (Primer Design) quantitative PCR reaction performed on a QuantStudio 6 Flex Real-Time PCR System (ThermoFisher), using gene-specific primers for Runt-related transcription factor 2 (RUNX2), osteocalcin, and glyceraldehyde 3-phosphate dehydrogenase (GAPDH), as an endogenous control. The results were analyzed using the $\Delta \Delta \mathrm{CT}$ method according to MIQE guidelines. ${ }^{24,25}$ The primer sequences were as follows: GAPDH Forward 5'-TTCTTTTGCGTC GCCAGCCGA-3', GAPDH Reverse 5'-GTGACCAGGCG CCCAATACGA-3'; RUNX2 Forward 5'-CCCGTGGCC TTCAAGGT-3', RUNX2 Reverse 5'-CGTTACCCGCCAT GACAGTA-3'; and osteocalcin Forward 5'-GGCAGCGA GGTAGTGAAGAG-3', osteocalcin Reverse 5'-CTCACAC ACCTCCCTCCT-3'. All primers were validated using total human cDNA standard curves, and have 90-110\% amplification efficiency.

\section{Alizarin Red S staining}

DPSCs were treated with DDM liposomes $(100 \mu \mathrm{g} / \mathrm{mL})$ for 35 days, fixed with $10 \%$ (v/v) formaldehyde, and incubated with $2 \%(w / v)$ Alizarin Red S (pH 4.2) for $20 \mathrm{~min}$. After staining, the cells were washed four times with deionized distilled water and images taken at $20 \times$ magnification.

\section{Statistical methods}

Statistical analysis, where appropriate, was conducted using a two-tailed paired Student's $t$-test comparing two groups. Data are expressed as mean \pm standard error of the mean.

\section{Results}

\section{DDM was encapsulated into liposomes} for delivery to cells

Liposomes encapsulating 0-100 $\mu \mathrm{g} / \mathrm{mL}$ DDM were formulated with an average size of $126.5 \pm 40 \mathrm{~nm}$ (Table 1) and an average polydispersity index (PDI) of 0.168 . There was no significant $(p>0.05)$ variation in size or PDI between liposomes encapsulating different DDM concentrations. The efficacy of the DDM encapsulation was calculated by measuring VEGF and TGF- $\beta 1$ release from lysed liposomes, growth factors known to be highly expressed in DDM. $^{26,27}$ One hundred micrograms per milliliter DDM liposomes encapsulated the greatest amount of VEGF and TGF- $\beta 1$, encapsulating 3.1 and $330 \mathrm{pg} / \mathrm{mL}$, respectively (Table 2). Fifty micrograms per milliliter DDM liposomes encapsulated $1.06 \mathrm{pg} / \mathrm{mL}$ VEGF and $96 \mathrm{pg} / \mathrm{mL}$ TGF- $\beta 1$, and $10 \mu \mathrm{g} / \mathrm{mL}$ DDM liposomes encapsulated $0.9 \mathrm{pg} / \mathrm{mL}$ VEGF and $126 \mathrm{pg} / \mathrm{mL}$ TGF- $\beta 1$. The calculated encapsulation efficiency for each growth factor was similar for $50 \mu \mathrm{g} / \mathrm{mL}$ DDM liposomes $(25.9 \%$ and $28.8 \%$ for VEGF and TGF- $\beta 1$, respectively), however, the encapsulation efficiency varied for $100 \mu \mathrm{g} / \mathrm{mL}$ DDM liposomes, with greater efficiency for TGF$\beta 1(146.7 \%)$ than VEGF $(39.0 \%)$. Due to the limit of detection of the ELISA Kits, encapsulation efficiencies for 1 and $10 \mu \mathrm{g} / \mathrm{mL}$ DDM liposomes were unable to be determined.

All DDM liposomes tested (DDM concentrations of 0,1 , $10,100 \mu \mathrm{g} / \mathrm{mL}$; liposome concentrations of $10 \mathrm{ng} / \mathrm{mL})$ caused no cytotoxic effects on a hDPSCs colony $(p>0.05)$, after 3, 9, or 21 days treatment (Fig. 1A).

\section{DDM liposomes promoted the chemotactic recruitment of hDPSCs}

Next, the effects of DDM liposomes on proliferation, survival, and recruitment of DPSCs, key events in dentin repair process, were tested. Liposomal treatments for $72 \mathrm{~h}$ had no significant $(p>0.05)$ change in cell proliferation,

Table 1. Size and Polydispersity Index of Demineralized Dentin Matrix Liposomes

\begin{tabular}{lcccc}
\hline & & $1 \mu \mathrm{g} / \mathrm{mL} \mathrm{DDM}$ & $10 \mu \mathrm{g} / \mathrm{mL} \mathrm{DDM}$ & $100 \mu \mathrm{g} / \mathrm{mL} \mathrm{DDM}$ \\
liposomes & liposomes & $124.2 \pm 39.5$ \\
\hline Average size \pm SD $(\mathrm{nm})$ & $122.9 \pm 37.6$ & $124.8 \pm 37$ & $134 \pm 46.1$ & 0.177 \\
PDI & 0.164 & 0.151 & 0.1825 & 125 \\
\hline
\end{tabular}

A Zetasizer Nano ZS was used to measure the average size and PDI of each batch of liposomes $(0-100 \mu \mathrm{g} / \mathrm{mL})$ by dynamic light scattering $(n=8 \pm \mathrm{SD})$.

DDM, demineralized dentin matrix; PDI, polydispersity index; SD, standard deviation; TBS, Tris-buffered saline. 
Table 2. Demineralized Dentin Matrix was Encapsulated into Liposomes for Delivery

\begin{tabular}{|c|c|c|c|c|}
\hline DDM liposomes & $0 \mu g / m L(T B S)$ & $10 \mu \mathrm{g} / \mathrm{mL}$ & $50 \mu \mathrm{g} / \mathrm{mL}$ & $100 \mu \mathrm{g} / \mathrm{mL}$ \\
\hline \multicolumn{5}{|l|}{ VEGF } \\
\hline VEGF in free $(\mathrm{pg} / \mathrm{mL})$ & 0 & Undetermined & $4.09 \pm 1.36$ & $7.73 \pm 0.45$ \\
\hline VEGF in intact liposomes (pg/mL) & $0.92 \pm 0.7$ & $3.03 \pm 3.03$ & $2.28 \pm 1.2$ & $3.33 \pm 0.99$ \\
\hline VEGF from lysed liposomes (pg/mL) & 0 & $0.91 \pm 0.91$ & $1.06 \pm 0.55$ & $3.18 \pm 1.86$ \\
\hline $\begin{array}{l}\text { \% encapsulation efficiency (VEGF from lysed } \\
\text { liposomes/VEGF in free } \times 100)\end{array}$ & 0 & Undetermined & $25.92 \%$ & $39.04 \%$ \\
\hline \multicolumn{5}{|l|}{ TGF- $\beta 1$} \\
\hline TGF- $\beta 1$ in free $(\mathrm{pg} / \mathrm{mL})$ & 0 & Undetermined & $333 \pm 98.2$ & $225 \pm 57.2$ \\
\hline TGF- $\beta 1$ in intact liposomes $(\mathrm{pg} / \mathrm{mL})$ & 0 & $171 \pm 90.5$ & $78 \pm 13.1$ & $168 \pm 3$ \\
\hline TGF- $\beta 1$ from lysed liposomes (pg/mL) & 0 & $126 \pm 78.5$ & $96 \pm 31.3$ & $330 \pm 18.2$ \\
\hline $\begin{array}{l}\% \text { encapsulation efficiency }(\mathrm{TGF}-\beta 1 \text { from lysed } \\
\text { liposomes/TGF- } \beta 1 \text { in free } \times 100)\end{array}$ & 0 & Undetermined & $28.82 \%$ & $146.66 \%$ \\
\hline
\end{tabular}

$0,10,50,100 \mu \mathrm{g} / \mathrm{mL}$ DDM liposomes were separated from unentrapped material by Sephadex G50 column filtration, then lysed using $1 \%$ (v/v) Triton-X to release encapsulated cargo, and subsequently used in a VEGF and TGF- $\beta 1$ enzyme-linked immunosorbent assay, with TBS and free DDM $(10,50$, and $100 \mu \mathrm{g} / \mathrm{mL})$ as controls. From the measured release of growth factor in free DDM and liposomal encapsulated DDM, encapsulation efficiencies for 10,50 , and $100 \mu \mathrm{g} / \mathrm{mL}$ DDM liposomes were calculated. $n=3 \pm$ standard error of the mean.

TGF- $\beta 1$, transforming growth factor- $\beta 1$; VEGF, vascular endothelial growth factor.

assessed by cell counts (Fig. 1B). In line with our previous findings, free DDM $(10 \mu \mathrm{g} / \mathrm{mL})$ treatment for $72 \mathrm{~h}$ promoted the survival of hDPSCs, ${ }^{6}$ as shown by the reduction in apoptotic marker Caspase 3/7 (Fig. 1C; $p<0.05$ ) using a Glo-Caspase 3/7 luciferase assay. However, DPSCs treated with different concentrations of DDM liposomes had no significant reduction in Caspase 3 activity $(p>0.05)$.

A Boyden transwell chemotaxis assay showed that TBS and DDM liposomes significantly $(p<0.0001)$ promote chemotactic recruitment of hDPSC (Fig. 2A, B). There was a dose-dependent increase in DPSC chemotaxis with increasing doses of DDM liposomes over $48 \mathrm{~h}$. TBS liposomes alone stimulated the chemotaxis of DPSC compared with the control $(p<0.0001)$, but there was further significant increase in chemotaxis when DPSCs were treated with $100 \mu \mathrm{g} / \mathrm{mL}$ DDM liposomes $(p<0.01)$.

\section{DDM liposomes promoted the expression of osteogenic markers in hDPSCs}

The effect of DDM liposomes on promoting osteogenic differentiation in hDPSCs was investigated via quantitative real-time PCR (qRT-PCR) for "osteodentin" markers, RUNX2, and osteocalcin, which are early and late markers of odontogenesis process. After 3 days, there was an increased trend $(p>0.05)$ in RUNX2 expression in DPSCs treated with free DDM ( $\sim 2$-fold increased) and the higher concentrations of DDM liposomes treatments (10 and $100 \mu \mathrm{g} / \mathrm{mL}$; 4- and 1.5-fold increase, respectively; Fig. 3A). This peak of expression was significantly lost in $10 \mu \mathrm{g} / \mathrm{mL}(p<0.001)$ and $100 \mu \mathrm{g} / \mathrm{mL}(p<0.0001)$ DDM liposome-treated hDPSCs at day 9 . The peak of expression was later in cells treated with free DDM and $1 \mu \mathrm{g} / \mathrm{mL}$ DDM liposomes as at day 9, and
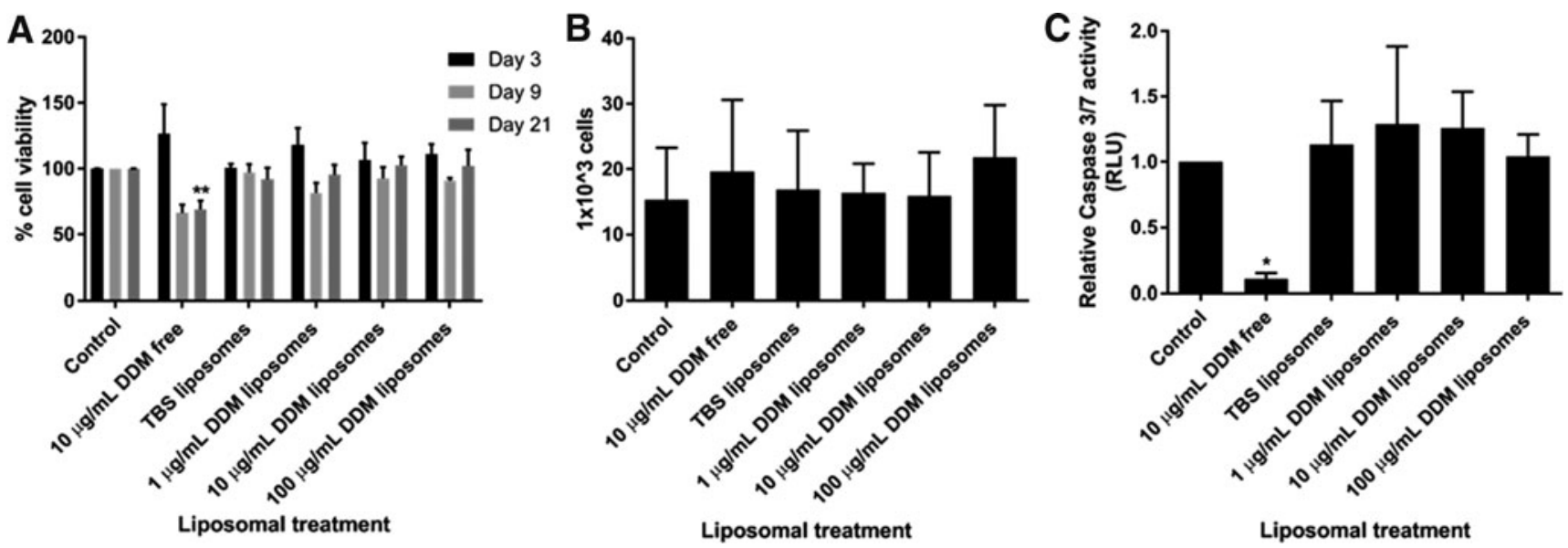

FIG. 1. DDM liposomes had no cytotoxic effects in hDPSCs. DPSCs were treated with different concentrations of DDM liposomes $(0-100 \mu \mathrm{g} / \mathrm{mL}$; liposome concentration of $10 \mu \mathrm{g} / \mathrm{mL})$ for 3,9 , and 21 days and then used in a MTT assay (A) to assess cell viability. The cells were then counted with a hemocytometer (B) or used in a Caspase-Glo 3/7 assay (C), which measures apoptotic caspase- 3 activity using a bioluminescence substrate. $n=3 \pm$ SEM significance is indicated by $* p<0.05$ and $* * p<0.01$ (unpaired Student's $t$-test compared to control). DDM, demineralized dentin matrix; DPSCs, dental pulp stem cells; hDPSCs, human dental pulp stem cells; MTT, 3-(4,5-dimethylthiazol-2-yl)-2,5-diphenyltertrazolium bromide; RLU, relative luminescence unit; SEM, standard error of the mean; TBS, Tris-buffered saline. 
A

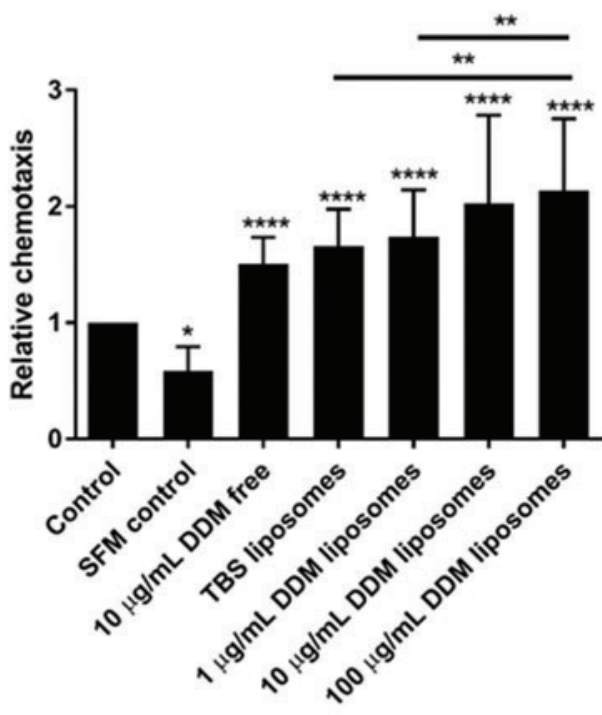

Liposomal treatment (100 ug/mL)
B
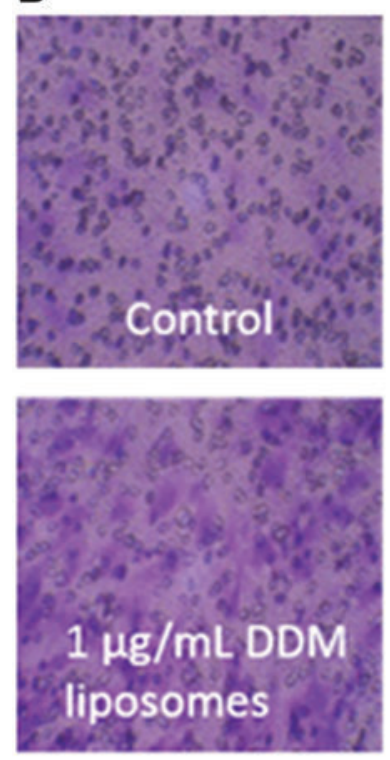
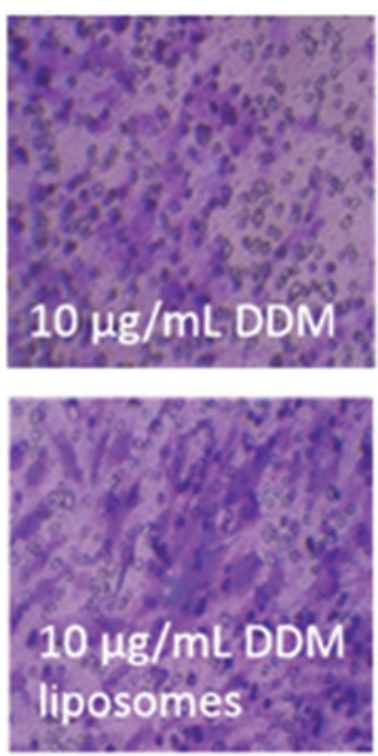
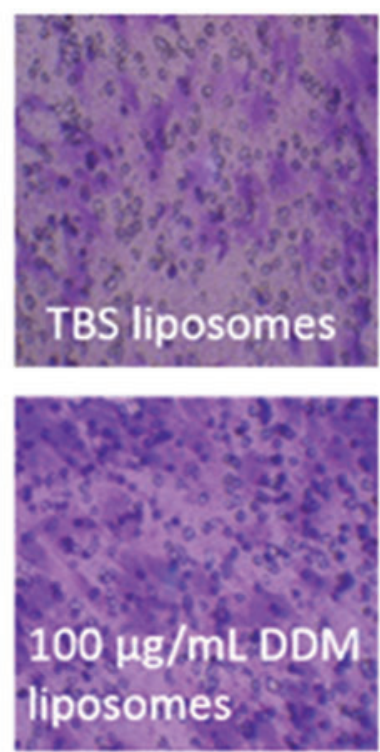

FIG. 2. DDM liposomes promoted the chemotaxis of hDPSCs in a dose-dependent manner. DPSCs were seeded into Boyden transwell inserts, placed on liposome treatments $(100 \mu \mathrm{g} / \mathrm{mL})$, SFM, free DDM $(10 \mu \mathrm{g} / \mathrm{mL})$, or control (basal $\alpha$-MEM) and allowed to pass through a $0.8 \mu \mathrm{m}$ membrane for $48 \mathrm{~h}$. Membranes were then fixed and stained with $0.1 \%(\mathrm{w} / \mathrm{v})$ crystal violet, respective photos were taken (B) and recruited cells counted (A).

$n=3 \pm$ SEM significance indicated by $* p<0.05, * * p<0.01$, and $* * * * p<0.0001$ (unpaired Student's $t$-test compared to control). SFM, serum-free media. Color images available online at www.liebertpub .com/tea there was a $\sim 4$-fold increase in RUNX2 expression compared with day 3 control ( $p>0.05)$. Of note, TBS liposomes induced significant $(p<0.05) \sim 1.2$-fold increase in RUNX2 expression at day 3, which was lost at day 9.

Free DDM and $1 \mu \mathrm{g} / \mathrm{mL}$ DDM liposomes caused a $\sim 12$-fold $(p<0.05)$ and $\sim 26$-fold $(p>0.05)$ increase in osteocalcin expression, respectively, after 9 days (Fig. 3B). In these conditions, the relative expression of osteocalcin decreased after 21 days of treatment. For the higher DDM liposome concentrations (10 and $100 \mu \mathrm{g} / \mathrm{mL}$ ), the levels of osteocalcin transcript significantly increased after 21 days of treatment $(p<0.05)$, compared with 9 days. Again, TBS liposomes caused a significant $(p<0.001)$ increase in osteocalcin messenger RNA levels after 21 days of culture, compared with day 9.

\section{DDM liposomes induced mineralization of hDPSCs}

Mineralization, a marker of late osteogenesis, was examined in hDPSCs treated with DDM liposomes. After 35 days, there was increased Alizarin Red S staining in hDPSC treated with DDM liposomes (10 and $100 \mu \mathrm{g} / \mathrm{mL}$ DDM) compared with untreated, osteogenic media and free DDM $(10 \mu \mathrm{g} / \mathrm{mL})$ controls (Fig. 3C). Interestingly, TBS liposomes also increased DPSC mineralization compared with the untreated controls.

\section{Discussion}

Dentin contains a "cocktail" of factors, ${ }^{3}$ including VEGF, fibroblast growth factor, epidermal growth factor, ${ }^{26}$ matrix metalloproteinases, and members of TGF- $\beta$ superfamily (TGF- $\beta 1,2,3,{ }^{27}$ bone morphogenetic protein 2,4 , and 7), which synergistically coordinate dentin repair, recruitment, and osteo-/odontoinduction of stem cells. ${ }^{5,28,29}$ In addition, small leucine-rich proteoglycans, biglycan and decorin, ${ }^{30}$ and dentin-specific molecules such as DSP ${ }^{14}$ and dentin phosphoprotein (DMP-1) have been shown to contribute toward DDM bioactivity. In line with this, we found, 

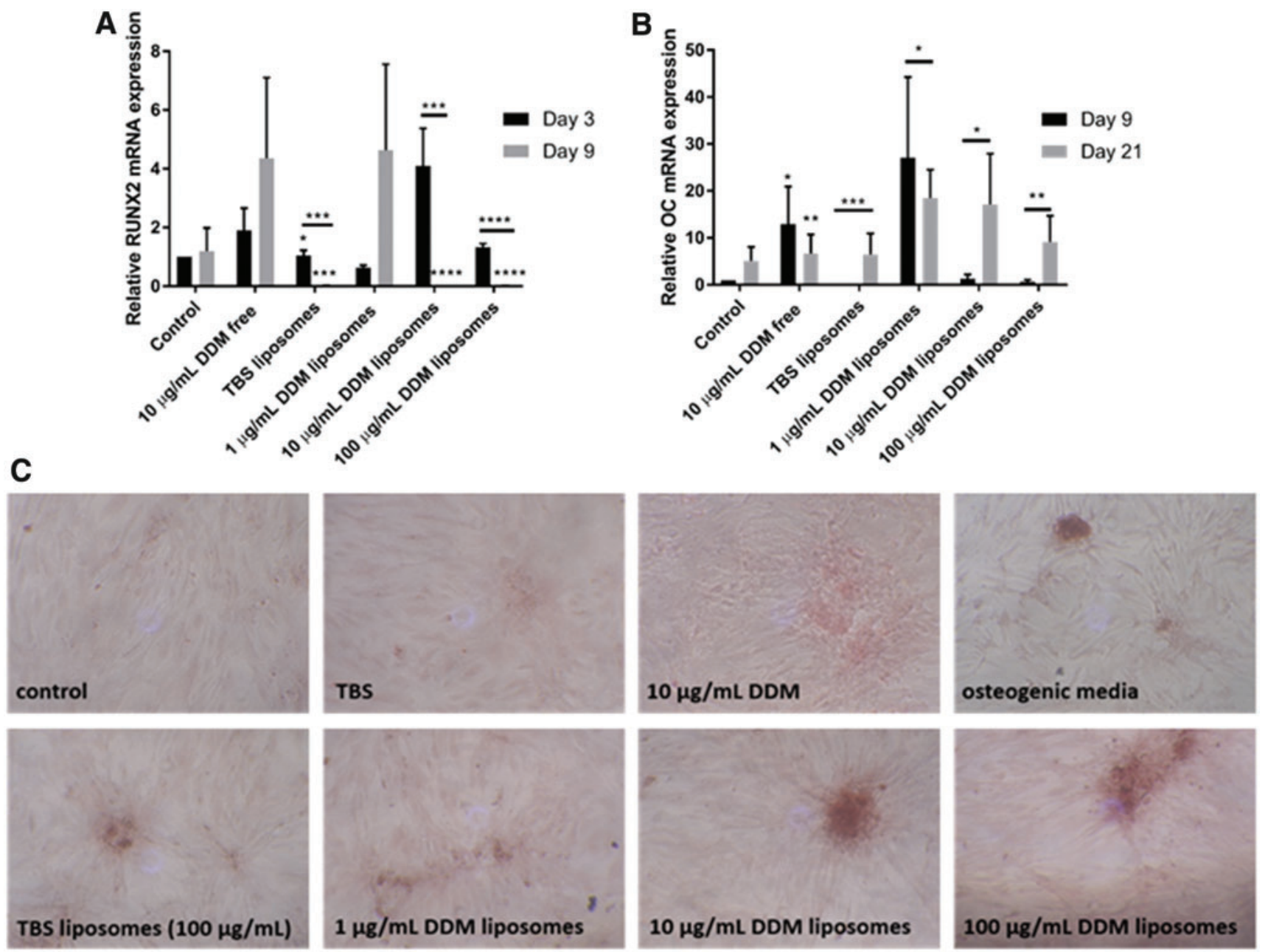

FIG. 3. DDM liposomes promoted the osteogenic differentiation of hDPSC progenitor cells. DPSCs were treated with DDM liposomes $(0-100 \mu \mathrm{g} / \mathrm{mL}$ DDM, $10 \mu \mathrm{g} / \mathrm{mL}$ liposome), free $10 \mu \mathrm{g} / \mathrm{mL}$, or control for DDM for 3, 9, and 21 days. qRTPCR was performed using primers to amplify RUNX2, an early osteodentine marker, at days 3 and 9 (A) and osteocalcin, a late osteodentine marker, at days 9 and 21 (B), their expression compared to endogenous control GAPDH. The data are shown relative to day 3 control (A) and day 9 control (B). After 35 days of treatment, the amount of calcium deposition was assessed by Alizarin Red S staining using 2\% (w/v) Alizarin Red S, cultures treated with $100 \mu \mathrm{g} / \mathrm{mL}$ DDM liposomes, and representative pictures taken at $20 \times$ magnification $(\mathbf{C}) . \quad n=3 \pm$ SEM significance indicated by $* p<0.05$, $* * p<0.01$, $* * * p<0.001$, and $* * * * p<0.0001$ (unpaired Student's $t$-test compared to control). GAPDH, glyceraldehyde 3-phosphate dehydrogenase; qRT-PCR, quantitative real-time PCR; RUNX2, Runt-related transcription factor 2. Color images available online at www.liebertpub.com/tea

when liposomes were used to deliver DDM to a human DPSC clone, they stimulated chemotactic recruitment, odontogenic differentiation, and biomineralization.

In vivo, for dentin regeneration to occur, DPSCs are first required to migrate toward tertiary dentin to the site of injury, where they subsequently proliferate and provide a source of progenitors for odontogenic differentiation to produce new dentin. ${ }^{1}$ In this study, biocompatible TBS phosphatidylserine liposomes were sufficient to stimulate the chemotactic recruitment of hDPSCs, and DDM liposomes further promoted DPSCs chemotaxis in a dose-dependent manner, suggesting that DDM liposomes are releasing their cargo to allow paracrine signaling. In this way, DDM liposomes are initiating the first crucial events in dentin repair. A previous study from our group ${ }^{7}$ showed that only low DDM doses $(0.1 \mu \mathrm{g} / \mathrm{mL})$ were able to promote migration of BMMSC, and higher doses $(1-10 \mu \mathrm{g} / \mathrm{mL})$ were inhibitory to migration. Similarly, several studies have demonstrated that low doses of DDM promote cellular wound healing through stimulating migration, differentiation, ${ }^{29,31}$ and angiogene$\mathrm{sis}^{32}$ however, higher doses were found to have an inhibitory effect. In this study, $10 \mu \mathrm{g} / \mathrm{mL}$ DDM promoted hDPSC migration and, despite being a smaller dose according to encapsulation efficacies, DDM liposomes promoted more migration than free DDM, we postulate that this is due to the slow, consistent release of multiple chemokines having a greater combined effect.

Liposomal delivery of growth factors has been used to promote wound healing, cardiac, cartilage, and bone regeneration. ${ }^{33-36}$ Many studies have profiled drug retention in liposomes over time and demonstrated that liposomes have a slower release rate of the encapsulated drug/growth factor compared to free drug. ${ }^{37-39}$ Giannoni and Hunziker ${ }^{35}$ observed that the rate of TGF- $\beta 1$ release from liposomes in 
fibrin clots was lower compared to free drug release over an initial 5-day period. A body of research ${ }^{40,41}$ has demonstrated that a sustained release of growth factors from biomaterials is more effective at producing a cellular response and driving mineralized tissue repair than an initial burst. Likewise, the sustained release of DDM from liposomes within a material is proposed to be more successful than the delivery of individual growth factors due to the synergistic multi-osteoinductive growth factors and matricellular components, which can sequester bioactivity and orchestrate endogenous dentin-pulp complex repair.

Encapsulation of DDM into liposomes allows for a sustained, controlled, local delivery ${ }^{42}$ of DDM over time, reducing the need for high doses of free DDM, which has a lengthy production time and uses a limited resource of noncarious human teeth. Research has recently shown that whole DDM is more effective at driving bone repair than individual fractions separated by heparin affinity chromatography, ${ }^{7}$ thus, a proportion of the entire DDM may be necessary to be encapsulated to drive full dental repair. To establish the amount of DDM encapsulation and therefore the dose of DDM administered to cells, single growth factor ELISAs were used for VEGF and TGF- $\beta 1$. This highlighted that the liposomes are likely to differentially encapsulate individual constituents of DDM, as TGF- $\beta 1$ had a much greater encapsulation efficiency at $100 \mu \mathrm{g} / \mathrm{mL}$ than VEGF (146.7\% compared to $39.0 \%)$. Therefore, it is difficult to assess the exact delivery of DDM constituents to cells using liposomal carriers. Further work is needed to assess the exact encapsulation in DDM liposomes and to delineate how DDM liposomes elicit their response, for example, through cargo release or uptake into DPSCs. The migration data suggest DDM release from liposomes, however, we cannot rule out that liposomes may enter cells by endocytosis or membrane fusion, as many have previously shown ${ }^{43,44}$ to deliver DDM components to produce the observed mineralizing phenotype.

We observed an increase in mineralization with control (TBS) liposomes, which was further increased when liposomes were loaded with bioactive DDM, suggesting that DDM liposomes are inducing differentiation. The biomineralization observed with control liposomes was likely to be the result of phosphatidylserine in the liposomal formulation. Phosphatidylserine is known to bind calcium ions to promote mineralization, ${ }^{45}$ and has previously been used to coat prosthetic implants, which has promoted osteoblast attachment, mineralization, and osseointegration in both in vitro and in vivo experiments. ${ }^{46,47}$ Control liposomes also promoted the expression of osteodentin markers, and chemotaxis, suggesting that the phosphatidylserine containing liposomal carrier is beneficial for delivering DDM for promoting mineralized tissue.

Data presented in this study suggest that liposomes are highly efficient at delivering low, sustained doses of DDM that are required for stimulating dental tissue repair. The dentin regeneration seen in vivo, referred to as tertiary dentin, has been reported to be histologically and biochemically similar to bone. ${ }^{48}$ In addition, some proteins that are classically considered as dentin-specific are downregulated in tertiary dentin (DSP and DMP-1). ${ }^{49}$ This study assessed therefore osteodentin markers RUNX2 and osteocalcin in response to DDM liposomes. RUNX2 is a key transcription factor involved in early osteogenesis and odontogenesis, but it is downregulated in terminal differentiation. ${ }^{50,51}$ This trend was observed in DPSCs treated with high concentrations of DDM liposomes $(10$ and $100 \mu \mathrm{g} /$ mL DDM), where RUNX2 expression was upregulated at day 3 , but significantly downregulated at day 9 . Osteocalcin is an extracellular dentin and bone matrix protein recognized as a late stage marker of odontoblast and osteoblast differentiation. ${ }^{52,53}$ Higher concentrations of DDM liposomes and free DDM induced osteocalcin expression after 21 days. Taken together, the analysis of markers suggests that DPSCs treated with DDM liposomes are undergoing differentiation into odontoblast-like cells, highlighting the potential therapeutic use of these liposomes in regenerative dentinogenesis.

Bioactive DDM liposomes could be applied in various biomaterials for hard-tissue engineering purposes. Members of our group have previously optimized a highly efficient liposomal drug delivery system in bone cements, ${ }^{54}$ integrating liposomes in polymethyl methacrylate bone cements with minimal integral artefacts. This study has particularly highlighted the potential use of these liposomes in restorative dental materials, for example, liposomes could be released from glass ionomer cements or modified hydrogels (Mourtas et al. ${ }^{55}$ ) to harness the tooth's natural repair mechanisms. Alternatively, the liposomes could even be directly applied to the pulp during a pulpotomy to enhance pulp dentin regeneration.

This work has shown that bioactive dentin growth factors and matrices can be incorporated and released from liposomes to recruit and differentiate DPSC, promoting dentinogenesis in vitro. The enhancement of dentin remineralization and activation of local DPSCs would, in turn, delay the progression of dental disease and thereby improve the longevity of dental restorations.

\section{Acknowledgments}

This work was supported by Medical Research Council (MRC) UK Regenerative Medicine Platform, Acellular Approaches for therapeutic delivery Hub Partnership award and a MRC research grant (G0900954).

\section{Disclosure Statement}

No competing financial interests exist.

\section{References}

1. Sloan, A.J., and Smith, A.J. Stem cells and the dental pulp: potential roles in dentine regeneration and repair. Oral Dis 2, 151, 2007.

2. Tziafas, D. Mechanisms controlling secondary initiation of dentinogenesis. Int Endod J 27, 61, 1994.

3. Smith, A.J., Scheven, B.A., Takahashi, Y., Ferracane, J.L., Shelton, R.M., and Cooper, P.R. Dentine as a bioactive extracellular matrix. Arch Oral Biol 57, 109, 2012.

4. Chun, S.Y., Lee, H.J., Choi, Y.A., et al. Analysis of the soluble human tooth proteome and its ability to induce dentin/tooth regeneration. Tissue Eng Part A 17, 181, 2011.

5. Bègue-Kirn, C., Smith, A., Ruch, J., et al. Effects of dentin proteins, transforming growth factor beta 1 (TGF beta 1) and bone morphogenetic protein 2 (BMP2) on the differentiation of odontoblast in vitro. Int J Dev Biol 36, 491, 1992. 
6. Lee, C.P., Colombo, J.S., Ayre, W.N., Sloan, A.J., and Waddington, R.J. Elucidating the cellular actions of demineralised dentine matrix extract on a clonal dental pulp stem cell population in orchestrating dental tissue repair. J Tissue Eng 6, 1, 2015.

7. Avery, S.J., Sadaghiani, L., Sloan, A.J., and Waddington, R.J. Analysing the bioactive makeup of demineralised dentine matrix on bone marrow mesenchymal stem cells for enhanced bone repair. Eur Cells Mater 34, 1, 2017.

8. Gomes, M.F., Destro, M.F., Banzi, É.C., et al. Optical density of bone repair after implantation of homogenous demineralized dentin matrix in diabetic rabbits. Braz Oral Res 22, 275, 2008.

9. Tziafas, D., Lambrianidis, T., and Beltes, P. Inductive effect of native dentin on the dentinogenic potential of adult dog teeth. J Endod 19, 116, 1993.

10. Reis-Filho, C.R., Silva, E.R., Martins, A.B., et al. Demineralised human dentine matrix stimulates the expression of VEGF and accelerates the bone repair in tooth sockets of rats. Arch Oral Biol 57, 469, 2012.

11. Lucarotti, P.S.K., Holder, R.L., and Burke, F.J.T. Outcome of direct restorations placed within the general dental services in England and Wales (Part 1): variation by type of restoration and re-intervention. J Dent 33, 805, 2005.

12. Lumley, P.J., Lucarotti, P.S.K., and Burke, F.J.T. Ten-year outcome of root fillings in the General Dental Services in England and Wales. Int Endod J 41, 577, 2008.

13. Neves, V.C.M., Babb, R., Chandrasekaran, D., and Sharpe, P.T. Promotion of natural tooth repair by small molecule GSK3 antagonists. Sci Rep 7, 39654, 2017.

14. Li, W., Chen, L., Chen, Z., et al. Dentin sialoprotein facilitates dental mesenchymal cell differentiation and dentin formation. SciRep 7, 1, 2017.

15. Graham, L., Cooper, P.R., Cassidy, N., Nor, J.E., Sloan, A.J., and Smith AJ. The effect of calcium hydroxide on solubilisation of bio-active dentine matrix components. Biomaterials 27, 2865, 2006.

16. Galler, K.M., Buchalla, W., Hiller, K., et al. Influence of root canal disinfectants on growth factor release from dentin. J Endod 41, 363, 2015.

17. Sadaghiani, L., Gleeson, H.B., Youde, S., Waddington, R.J., Lynch, C.D., and Sloan, A.J. Growth factor liberation and DPSC response following dentine conditioning. J Dent 95, 1298, 2016.

18. Bulbake, U., Doppalapudi, S., Kommineni, N., and Khan, W. Liposomal formulations in clinical use: an updated review. Pharmaceutics 9, 1, 2017.

19. Monteiro, N., Martins, A., Reis, R., and Neves, N. Liposomes in tissue engineering and regenerative medicine. J R Soc Interface 11, 20140459, 2014.

20. Satsangi, N., Satsangi, A., Glover, R., Ong, J.L., and Satsangi, R. Osteoblast response and calcium deposition on phospholipid modified surfaces. J Mater Sci Mater Med 15, 693, 2004.

21. Bosetti, M., Lloyd, A.W., Santin, M., Denyer, S.P., and Cannas M. Effects of phosphatidylserine coatings on titanium on inflammatory cells and cell-induced mineralisation in vitro. Biomaterials 26, 7572, 2005.

22. Alraies, A., Alaidaroos, N.Y.A., Waddington, R.J., Moseley, R., and Sloan, A.J. Variation in human dental pulp stem cell ageing profiles reflect contrasting proliferative and regenerative capabilities. BioMed Cent Cell Biol 18, $1,2017$.
23. Torchilin, V.P., and Weissig, V. Liposomes: A Practical Approach, 2nd ed. Oxford and New York: OUP Oxford, 2003.

24. Livak, K.J., and Schmittgen, T.D. Analysis of relative gene expression data using real-time quantitative PCR and the 2(-Delta Delta C(T)) method. Methods 25, 402, 2001.

25. Bustin, S., Benes, V., and Garson, J. The MIQE guidelines: minimum information for publication of quantitative realtime PCR experiments. Clin Chem 55, 611, 2009.

26. Roberts-Clark, D., and Smith, A. Angiogenic growth factors in human dentine matrix. Arch Oral Biol 45, 1013, 2000.

27. Sloan, A., Perry, H., Matthews, J., and Smith, A.J. Transforming growth factor-Beta isoform expression in mature human healthy and carious molar teeth. Histochem J 32, 247, 2000.

28. Casagrande, L., Demarco, F.F., Zhang, Z., Araujo, F.B., Shi, S., and Nör, J.E. Dentin-derived BMP-2 and odontoblast differentiation. J Dent Res 89, 603, 2010.

29. Liu, G., Xu, G., Gao, Z., et al. Demineralized dentin matrix induces odontoblastic differentiation of dental pulp stem cells. Cells Tissues Organs 201, 65, 2016.

30. Haruyama, N., Sreenath, T.L., Suzuki, S., et al. Genetic evidence for key roles of decorin and biglycan in dentin mineralization. Matrix Biol 28, 129, 2009.

31. Widbiller, M., Eidt, A., Lindner, S.R., Schweikl, H., Buchalla, W., and Galler, K.M. Dentine matrix proteins: isolation and effects on human pulp cells. Int Endod J 2017 [Epub ahead of print]; doi:10.1111/iej.12754.

32. Zhang, R., Cooper, P.R., Smith, G., Nör, J.E, and Smith, A.J. Angiogenic activity of dentin matrix components. J Endod 37, 26, 2011.

33. Alemdaroğlu, C., Degim, Z., Celebi, N., Sengezer, M., Alömeroglu, M., and Nacar, A. Investigation of epidermal growth factor containing liposome formulation effects on burn wound healing. J Biomed Mater Res A 85, 271, 2008.

34. Scott, R.C., Rosano, J.M., Ivanov, Z., et al. Targeting VEGF-encapsulated immunoliposomes to MI heart improves vascularity and cardiac function. FASEB J 23, 3361, 2009.

35. Giannoni, P., and Hunziker, E.B. Release kinetics of transforming growth factor-beta1 from fibrin clots. Biotechnol Bioeng 83, 121, 2003.

36. Marquez, L., de Abreu, F.A., Ferreira, C.L., Alves, G.D., Miziara, M.N., and Alves, J.B. Enhanced bone healing of rat tooth sockets after administration of epidermal growth factor (EGF) carried by liposome. Injury 44, 558, 2013.

37. Panwar, P., Pandey, B., Lakhera, P.C., and Singh, K.P. Preparation, characterization, and in vitro release study of albendazole-encapsulated nanosize liposomes. Int J Nanomedicine 5, 101, 2010.

38. Hua, S. Comparison of in vitro dialysis release methods of loperamide-encapsulated liposomal gel for topical drug delivery. Int J Nanomedicine 9, 735, 2014.

39. Ohnishi, N., Tomida, H., Ito, Y., Tahara, K., and Takeuchi, H. Characterization of a doxorubicin liposome formulation by a novel in vitro release test methodology using columnswitching high-performance liquid chromatography. Chem Pharm Bull 62, 538, 2014.

40. Furuya, H., Tabata, Y., and Kaneko, K. Bone regeneration for murine femur fracture by gelatin hydrogels incorporating basic fibroblast. Tissue Eng Part A 20, 1531, 2014.

41. Jeon, O., Song, S.J., Yang, H.S., et al. Long-term delivery enhances in vivo osteogenic efficacy of bone 
morphogenetic protein-2 compared to short-term delivery. Biochem Biophys Res Commun 369, 774, 2008.

42. Allen, T., and Cullis, P. Liposomal drug delivery systems: from concept to clinical applications. Adv Drug Deliv Rev 65, 36, 2013.

43. Fahr, A., van Hoogevest, P., May, S., Bergstrand, N.S., and Leigh, M.L. Transfer of lipophilic drugs between liposomal membranes and biological interfaces: consequences for drug delivery. Eur J Pharm Sci 26, 251, 2005.

44. Pollock, S., Antrobus, R., Newton, L., et al. Uptake and trafficking of liposomes to the endoplasmic reticulum. FASEB J 24, 1866, 2010.

45. Genge, B.R., Wu, L.N.Y, and Wuthier, R.E. Differential fractionation of matrix vesicle proteins: further characterization of the acidic phospholipid-dependent $\mathrm{Ca} 2+$-binding proteins. J Biol Chem 265, 4703, 1990.

46. Satsangi, A., Satsangi, N., Glover, R., Satsangi, R.K., and Ong, J.L. Osteoblast response to phospholipid modified titanium surface. Biomaterials 24, 4585, 2003.

47. Merolli, A., Bosetti, M., Giannotta, L., et al. In vivo assessment of the osteointegrative potential of phosphatidylserinebased coatings. J Mater Sci Mater Med 17, 789, 2006.

48. Goldberg, M., Kulkarni, A.B., Young, M., and Boskey, A. Dentin: structure, composition and mineralization. Front Biosci 1, 711, 2011.

49. Moses, K.D., Butler, W.T., and Qin, C. Immunohistochemical study of small integrin-binding ligand, N-linked glycoproteins in reactionary dentin of rat molars at different ages. Eur J Oral Sci 114, 216, 2006.

50. Komori, T. Regulation of osteoblast differentiation by Runx2. Adv Exp Med Biol 658, 43, 2009.

51. Chen, S., Rani, S., Wu, Y., et al. Differential regulation of dentin sialophosphoprotein expression by Runx 2 during odontoblast cytodifferentiation. J Biol Chem 280, 29717, 2005.

52. Nakashima, K., and Crombrugghe, B.D. Transcriptional mechanisms in osteoblast differentiation and bone formation. Trends Genet 19, 458, 2003.

53. Papagerakis, P., Berdal, A., Mesbah, M., et al. Investigation of osteocalcin, osteonectin, and dentin sialophosphoprotein in developing human teeth. Bone 30, 377, 2002.

54. Ayre, W.N., Birchall, J.C., Evans, S.L., and Denyer, S.P. A novel liposomal drug delivery system for PMMA bone cements. J Biomed Mater Res B Appl Biomater 104, 1510, 2016.

55. Mourtas, S., Fotopoulou, S., Duraj, S., Sfika, V., Tsakiroglou, C., and Antimisiaris, S.G. Liposomal drugs dispersed in hydrogels. Effect of liposome, drug and gel properties on drug release kinetics. Colloids Surf B Biointerfaces 55, 212, 2007.

Address correspondence to: Genevieve E. Melling, PhD

Department of Oral and Biomedical Sciences School of Dentistry Cardiff University Cardiff CF14 4XY United Kingdom

E-mail: gmelling@brookes.ac.uk

Received: September 29, 2017

Accepted: January 8, 2018

Online Publication Date: February 20, 2018 